\title{
IMPLEMENTASI KOMUNIKASI EFEKTIF KEPALA SEKOLAH DALAM MENINGKATKAN MOTIVASI KERJA GURU DI SDN MEKARJAYA 30 DEPOK
}

\author{
Iis Dewi Lestari \\ Program Studi Informatika, Universitas Indraprasta PGRI \\ Iisdewi_lestari@yahoo.co.id
}

\begin{abstract}
Abstrak
Setiap guru harus memiliki motivasi kerja sebagai dorongan yang kuat baik dari dalam diri maupun dari luar untuk meningkatkan prestasi dalam pekerjaannya. Motivasi kerja guru dapat berasal dari kepala sekolah. Salah satunya adalah dengan memiliki komunikasi efektif yang dilakukan oleh kepala sekolah terhadap guru. Komunikasi yang efektif di sebuah sekolah merupakan hal yang sangat penting agar terciptanya suasana kerja yang harmonis. Dengan itu, peran kepala sekolah sangat besar untuk mewujudkan sekolah yang nyaman dan bersinergi. Tujuan dari penelitian ini adalah untuk mengetahui bagaimana implementasi kepala sekolah dalam penggunaan komunikasi efektif untuk meningkatkan motivasi kerja guru. Metodologi penelitian ini adalah deskriptif . Teknik pengumpulan data dilakukan dengan wawancara, pengamatan dan studi kepusatakaan. Teknik analisis data dalam penelitian ini dengan menggunakan reduksi data, penyajian data, dan penarikan kesimpulan. Hasil penelitian ini adalah kepala sekolah di SDN Mekarjaya 30 Depok dapat mengimplementasikan komunikasi efektif dengan guru. Hal ini dapat dilihat dari pemilihan saluran dalam berkomunikasi yang tepat oleh kepala sekolah, kepala sekolah berusaha memahami karakter dan kepribadian guru, kepala sekolah menggunakan bahasa tubuh sebagai penekanan dari informasi yang disampaikan untuk mudah dipahami oleh guru, Guru memberikan umpan balik dengan bentuk empati yang diwujudkan dengan memiliki motivasi kerja yang tinggi.
\end{abstract}

Kata kunci: Komunikasi efektif, Kepala sekolah, Motivasi Kerja

\begin{abstract}
Every teacher must have work motivation as a motivate from intrinsic and extrinsic to increase their jobs. Teacher work motivation can get from their headmaster. Headmaster have effectiveness communication to their teacher at school. Effectivenes communication is important to create the culture of organization at school with harmonious. Contribution of headmaster is important to have good school with positive energy and comfortable. Aim the research is to describe how the headmaster in using effectiveness communication to increase teacher work motivation at SDN Mekarjaya 30 Depok. The method of this research is descriptive. Data was collected by in the interview, observation, and literatue study. Data analysis was performed by data reduction, data presentation and conclusion on verifications. The results of this research are headmaster in SDN Mekarjaya 30 Depok implemented the effectiveness communication to the teacher. It can see from the good choosen channel by headmaster to get effectiveness communication, headmaster understand teacher's personality and character. Beside that headmaster using body language as a emphasis about the information to easy understand And teacher give the feed back with emphaty and have work motivation.
\end{abstract}

Keyword: Effectiveness Communication, Headmaster, Work Motivation

\section{PENDAHULUAN}

Motivasi kerja memiliki nilai fokus pada dorongan diri seseorang dan bagaimana kebutuhan tersebut di prioritaskan dalam pekerjaannya. Guru dalam menjalankan tugasnya harus memiliki motivasi kerja yang tinggi agar menghasilkan peserta didik yang berkualitas dan meningkatkan mutu pendidikan. Peningkatan motivasi kerja guru dapat diiringi dengan kemampuan komunikasi yang efektif dari kepala sekolah karena motivasi juga dapat berasal dari luar diri seseorang, salah satunya adalah dari kepala sekolah. Motivation refers to forces within an individual that account for the level, 
direction, and persistence of effort expended at work [9].

Komunikasi merupakan kekuatan pembentuk utama dalam organisasi. Dengan adanya komunikasi yang dapat dijalankan secara efektif maka situasi dalam pekerjaan akan lebih dinamis. Komunikasi antar manusia tidak tergantung pada teknologi tetapi lebih kepada kekuatan dalam diri dan lingkungannya. Tujuan komunikasi menurut Sam [2]

1. Agar yang disampaikan oleh komunikator dapat dimengerti oleh komunikan

2. Agar dapat memahami orang lain

3. Agar pendapat kita diterima orang

4. Menggerakan orang untuk melakukan sesuatu.

Dalam sebuah organisasi, komunikasi adalah prasyarat dasar untuk mencapai strategi dalam sebuah organisasi. Adanya keraguan bahwa komunikasi kurang memiliki peran penting dalam keefektifan manajerial menandakan bahwa komunikasi yang tidak efektif sering terjadi sebagai akar semua permasalahan di dunia [3].

Komunikasi adalah salah satu hal yang terpenting dalam sebuah organisasi karena dapat berdampak pada hasil kerja organisasi tersebut. George menyatakan bahwa "communication the sharing of information between two or more individuals or groups to reach a common understanding, effective communication is important in organization because it affects practically every aspect of organizational behavior"'[4]. Komunikasi di lingkungan sekolah khususnya yang dilakukan oleh kepala sekolah terhadap guru menjadi hal yang sangat penting. Hal ini dikarenakan kepala sekolah memiliki peran yang sangat penting dalam kemajuan sekolah khususnya meningkatkan motivasi kerja guru. Jika komunikasi dapat berjalan efektif maka dipastikan guru memiliki motivasi kerja yang tinggi sebagai jawaban atau respon yang dinyatakan dalam diri guru tersebut.

Anggota dalam sebuah organisasi harus dapat memahami kepribadian, perilaku dan nilai-nilai yang berlaku pada saat berkomunikasi. Dalam hal ini, kepala sekolah harus dapat mengetahui dasar dari menciptakan komunikasi yang efektif adalah dengan memahami beberapa nilai yang harus dipahami pada saat berkomunikasi dengan guru. Kepala sekolah harus memahami karakter, kepribadian masing-masing guru sehingga kepala sekolah pada saat berkomunikasi dapat lebih efektif dan mudah dimengerti oleh guru sebagai penerima pesan. Jika komunikasi efektif dapat dilakukan oleh kepala sekolah dengan baik maka motivasi kerja guru akan meningkat.

\section{METODE}

Metode penelitian ini adalah deksriptif kualitatif. Penelitian ini melakukan wawancara, observasi, dan studi kepustakaan. Adapun teknik analisis data dalam penelitian ini adalah reduksi data, penyajian data, dan simpulan.

\section{HASIL DAN PEMBAHASAN}

Hasil penelitian yang dilakukan di SDN Mekarjaya 30 Depok diketahui bahwa Ibu Kepala Sekolah Kristianti, S.Pd dapat mengimplementasikan komunikasi dengan efektif kepada guru-guru. Hal ini dapat dilihat dari motivasi kerja yang tinggi dimiliki oleh guru-guru. Dari hasil observasi kepala sekolah menggunakan media tatap muka dalam kegiatan rapat atau breifing pada saat memberikan informasi secara formal. Dari komunikasi tersebut, guru langsung memberikan umpan balik dengan mengerjakan arahan yang disampaikan oleh kepala sekolah. Disamping menggunakan media tatap 
muka, kepala sekolah juga menggunakan surat edaran secara tertulis kepada guru dan warga sekolah terkait jadwal dan kegiatan yang akan berlangsung di sekolah seperti kegiatan ulang tahun kemerderkaan RI, kegiatan pramuka, UTS, UKK, dll.

Function of communication menurut George [5] :

1. Providing knowledge

About company goals, how to perform a job, standards for acceptable behavior, needed changes and so on.

2. Expressing Feeling and emotions Such as positive and negative moods, excitiement and anger

3. Motivating organizational members For example, by determaning valences, raising expectancies and instrumentalities, assigning specific and difficult goals and giving feedback

4. Controlling and coordinating group activities

For example by reducing social loafting, communicating roles, rules and norms and avoiding duplication of effort.

Komunikasi memiliki fungsi yang cukup berarti dalam sebuah organisasi. Ketika berkomunikasi maka ada transfer informasi atau ilmu yang akan disampaikan oleh pengirim pesan. Dalam berkomunikasi juga dapat memperlihatkan ekspresi dan emosi yang dapat dimunculkan dari pengirim pesan kepada penerima pesan. Selain itu, memberikan motivasi kepada lawan bicara dapat ditumbuhkan melalui komunikasi yang efektif. Komunikasi juga menjadi pengendali dalam sebuah tim atau kelompok organisasi. Dengan berkomunikasi dapat mengendalikan hal baik dan buruk dalam sebuah organisasi.

Menurut William F. Glueck dalam Sam , komunikasi terbagi menjadi dua yaitu komunikasi interpersonal dan komunikasi organisasi. Sedangkan Syarat-syarat komunikasi antara lain source (orang, lembaga, buku), saluran, pesan, komunikan dan efek [2].

Mc Shane dalam buku Organizational Behavior [4] menyatakan bahwa " the comunication efectiveness depends on the ability of sender and receiver to efficiently and accurately encode and decode information. Four factors the effectiveness communication :

1. The sender's and receiver's ability and motivation to communicate through the communication channel.

2. The extent to which both parties have similiar codebooks dictionaries of symbols, language, gestures, idioms and others tools.

3. The extent to which both parties have shared mental models about the topic's context.

4. Sender's experience at communicating the message.

Dari pernyataan di atas maka dapat diketahui bahwa dalam melakukan komunikasi efektif hal-hal yang dibutuhkan adalah kedua belah pihak yang berkomunikasi sudah mengetahui media mana yang akan dipilih untuk melakukan komunikasi. Setelah itu menggunaan bahasa tubuh juga menjadi hal penting agar penyampaian informasi yang diterima dapat sesuai dengan apa yang disampaikan oleh pengirim pesan. Adanya umpan balik menandakan bahwa komunikasi tersebut dapat berjalan dengan efektif. Non verbal communication occurs through facial expressions, body motions, eye contact, and other physical gestures. In interpersonal comunication is important to understand the barries that can easily create communication problems [9]. Kepala sekolah SDN Mekarjaya 30 dalam berkomunikasi menggunakan komunikasi 
baik secara verbal dan non verbal. Dari hasil penelitian yang sebelumnya menyatakan bahwa $93 \%$ komunikasi non verbal (ekspresi wajah, gerakan tubuh, vocietone) memiliki kontribusi yang sangat penting dalam berkomunikasi [1]. Kepala sekolah dapat menentukan jenis komunikasi mana yang akan digunakan dan pemilihan media yang tepat pada saat berkomunikasi sehingga guru dapat memahami informasi ataupun arahan yang disampaikan kepala sekolah.

Communication is the glue that holds organizations together. It is the way we share information, ideas, goals, directions, expectations, feeling and emotions in the context of coordinated action[9]. Dengan berkomunikasi, komunikan atau pengirim pesan dapat memberikan informasi, arahan, ide, emosi dan perasaan terhadap komunikan. Kepala sekolah di SDN Mekarjaya 30 Depok dapat mengimplementasikan komunikasi dengan efektif, hal ini ditandai dengan selalu tercapainya tujuan yang disampaikan oleh kepala sekolah kepada guru-guru. Baik secara personal maupun grup. Kepala sekolah SDN Mekarjaya 30 lebih sering menggunakan media tatap muka dalam berkomunikasi, hal ini dikarenakan dapat menghindari terjadinya kesalahpahaman antar kedua belah pihak. Namun, tidak jarang juga kepala sekolah menggunakan media whatsapp sebagai komunikasinya kepada guru-guru. Namun, respon dan tujuan lambat tercapai jika komunikasi dalam memberikan arahan atau informasi melalui media tersebut.

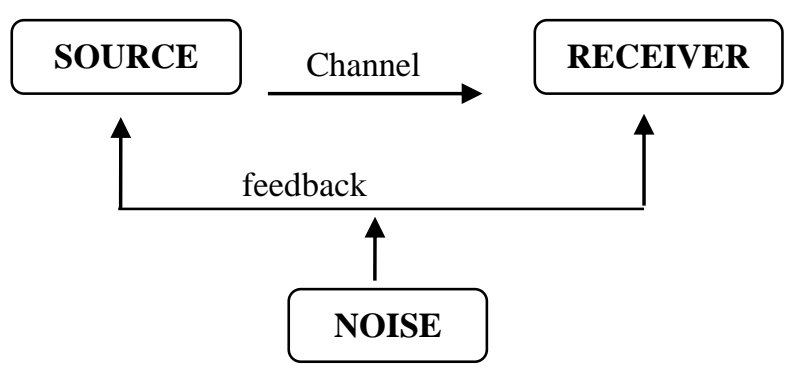

Sumber: Schemerhorn dalam buku Organizational Behavior

Gambar 1: The Communication Process

Hal ini didukung pula seperti yang dinyatakan Sutapa bahwa komunikasi yang efektif tergantung dari pengirim pesan dalam penyampaiannya dan penerima pesan untuk memahami pesan yang diterimanya [10]. Bentuk umpan balik ini dapat dilihat dari motivasi kerja guru sebagai pernyataan bahwa komunikasi yang dilakukan kepala sekolah kepada guru efektif. Tiga elemen motivasi kerja menurut George yaitu direction, effort and persistence [5]. Dilihat dari ketiga elemen tersebut kita dapat mengetahui apakah seseorang memiliki motivasi kerja yang tinggi atau tidak terhadap pekerjaannya. Hal itu dapat dilhat dari arah kerja, usaha kerja dan ketekunan seseorang. Guru di SDN Mekarjaya 30 memiliki tingkat kedisiplinan yang tinggi dilihat dari kehadiran, kelengkapan administrasi dan selalu berpartisipasi dalam kegiatan yang diselenggarakan sekolah. Hal senada juga disampaikan oleh Newstroom yang menyatakan bahwa "work motivation has three elements of it. Direction, effort provided and pesistence [6]".

Barnard dalam Luthans [3] menyatakan bahwa ada tujuh faktor yang penting dalam berkomunikasi dalam organisasi antara lain:

1. Saluran komunikasi sebaiknya diketahui secara pasti

2. Sebaiknya ada saluran komunikasi formal yang pasti bagi setiap anggota organisasi 
3. Saluran komunikasi sebaiknya berlangsung sesingkat mungkin

4. Menggunakan saluran komunikasi formal dan lengkap

5. Orang yang bertindak sebagai pusat komunikasi sebaiknya kompeten

6. Saluran komunikasi sebaiknya tidak terganggu pada saat organisasi berfungsi

7. Setiap komunikasi sebaiknya diotentikasi

Communcation flow [9]:

1. Downward communication, follows the chain of command from top to bottom

2. Upward communication is the flow of messages from lower to higher organizational levels.

3. Lateral communication is the flow of messages at the same levels across organization.

Untuk memahami komunikasi yang efektif baik itu secara interpersonal maka hal yang harus dipahami adalah jenis arus komunikasi. Komunikasi kepala sekolah dengan guru termasuk kedalam komunikasi ke bawah. Komunikasi yang terjadi antara kepala sekolah dengan guru seperti :

1. Memberi arahan tugas tentang instruksi kerja

2. Memberi informasi mengenai prosedur organisasi

3. Memberi tahu bawahan tentang kinerja mereka

For organizations, managers should provide intrinsic as well as extrinsic incentives. They need to make the work interisting, provide recognition and support enployee growth and development [8]. Dapat diketahui bahwa kepala sekolah sebagai pimpinan dapat memberikan motivasi kerja bagi guru, membuat guru nyaman dalam bekerja, berkomunikasi dan memberikan dukungan serta saran yang membangun untuk kemajuan sekolah.

Karakteristik umpan balik menurut Luthans dan Martino untuk komunikasi yang efektif dan tidak efektif dapat dijelaskan sebagai berikut[3]:

\begin{tabular}{cll}
\hline No & Komunikasi Eefektif & $\begin{array}{l}\text { Komunikasi tidak } \\
\text { efektif }\end{array}$ \\
\hline 1 & $\begin{array}{l}\text { Dimaksudkan untuk } \\
\text { membantu karyawan }\end{array}$ & $\begin{array}{l}\text { Bermaksud } \\
\text { meremehkan } \\
\text { karyawan }\end{array}$ \\
2 & Spesifik & Umum \\
3 & Deskriptif & Evluatif \\
4 & Berguna & Tidak tepat guna \\
5 & Tepat waktu & Tidak tepat waktu \\
6 & Memperhatikan & Membuat \\
& karyawan untuk & karyawan \\
& memberikan umpan & defensif \\
& balik & Tidak dapat \\
7 & Jelas & dipahami \\
& Tidak akurat \\
\hline
\end{tabular}

Kepala sekolah SDN Mekarjaya 30 dapat melihat kesempatan dan peluang untuk berkomunikasi baik secara formal maupun non formal. Kepala sekolah sebagai pimpinan memang sudah sepantasnya memahami waktu, kegunaan, media, dan memahami karakter komunikan untuk menghasilkan komunikasi yang efektif. Hal ini didukung dari hasil wawancara dengan Guru kelas1 di SDN Mekarjaya 30 bernama Ibu Ijah, S.Pd yang menyatakan bahwa kepala sekolah memiliki kemampuan komunikasi yang baik untuk dapat sekaligus menumbuhkan motivasi kerja guru. Hal ini dikarenakan setiap berkomunikasi dengan guru, kepala sekolah selalu memberikan informasi yang akurat dan spesifik serta jelas dalam berkomunikasi baik verbal dan non verbal ditambahkan pula dengan bahasa tubuh untuk menegaskan pesan yang disampaikan dengan baik. Selain itu, menurut guru lainnya yaitu Ibu Esih, S.Pd menyampaikan bahwa kepala sekolah lebih efektif menggunakan media komunikasi dengan tatap muka karena lebih valid dan 
akurat. Meskipun sering juga menggunakan whatsapp dalam berkomunikasi, namun dirasa respon dari guru agak lambat. Pernyataan tersebut didukung pula oleh Schemerhorn menyatakan bahwa saluran paling efektif dalam berkomunikasi dapat diurutkan sebagai berikut [9] : The richest channels are (1) face to face, (2) Telephone, (3) video conferences, (3) instant mesagging, (4) e-mail, (5) letters.

Jelas bahwa jika kepala sekolah dapat mengimplementasikan komunikasi dengan efektif maka umpan balik dari guru sebagai komunikan akan berguna dan cepat tanggap. Hal ini akan meningkatkan motivasi kerja guru itu sendiri, seperti yang disampaikan oleh M. George "Work motivation can be defined as the psychological forces within a person that determine the direction of a person's behavior in an organization, effort level, and persistence in the face obstacles. Three elements are direction of behavior,level of effort, and level of persistences" [5].

Steven Covey dalam Hassa dan Lina [1] menyatakan bahwa ada lima hal penting untuk membangun komunikasi efektif antara lain:

1. Usaha untuk mengerti orang lain

2. Kemampuan untuk memenuhi komitmen

3. Kemampuan untuk menjelaskan harapan

4. Jika terjadi kesalahan segera minta maaf

5. Kemampuan memperihatkan integritas.

Raharja dalam penelitiannya menyatakan bawa [7] motivasi kerja guru adalah faktor yang mempengarui guru untuk menghasilkan prestasi yang lebih baik dalam pekerjaannya. Motivasi ini dapat diperoleh secara intrinsik dan ekstrinsik.

\section{SIMPULAN}

1. Kepala sekolah di SDN Mekarjaya 30 Depok dapat mengimplementasikan komunikasi yang efektif dengan guru. Hal ini dapat dilihat dari :

- Pemilihan saluran dalam berkomunikasi yang tepat oleh kepala sekolah.

- Kepala sekolah berusaha memahami karakter dan kepribadian guru

- Kepala sekolah menggunakan bahasa tubuh sebagai penekanan dari informasi yang disampaikan untuk mudah dipahami oleh guru

- Guru memberikan umpan balik dengan bentuk empati yang diwujudkan dengan memiliki motivasi kerja yang tinggi

2. Iklim kerja di SDN Mekarjaya 30 Depok terasa harmonis dan selaras hal ini dikarenakan kepala sekolah dapat berkomunikasi dengan efektif kepada guru. Kepala sekolah dalam kedinasan melakukan rapat untuk berkomunikasi dengan guru secara formal. Dalam bentuk tertulis juga dilakukan oleh kepala sekolah sebagai bentuk komunikasi melalui surat edaran seperti peraturan, jadwal uts, kenaikan kelas, dll.

3. Peran kepala sekolah dalam mengimplementasikan komunikasi yang efektif memiliki dampak yang besar bagi peningkatan kinerja dan motivasi kerja guru.

\section{DAFTAR PUSTAKA}

[1] Hassa dan Lina. "Efektivitas Komunikasi dalam Organisasi”. Jurnal Manajemen Vol. 7 No. 4 tahun 2009.

[2] Sam, Hissam. "Pengertian Komunikasi Menurut Para Ahli”, 2014, [Online]. Tersedia:https://www.dosenpendidika n.com [diakses 13 November 2018]. 
[3] Luthans, Fred. "Perilaku Organisasi Terjemahan Oleh Vivin Andhika". Yogyakarta: Andi Offset, 2006.

[4] Mc Shane. "Organziational Behavior”. USA: McGraw Hill, 2010

[5] M.George, Jennifer. "Organizational Behavior". USA: Pearson Prentice Hall, 2005.

[6] Newstroom, John W. "Organizational Behavior". USA : Mc Graw Hill, 2007.

[7] Rahardja, Allice. "Hubungan Komunikasi Antar Pribadi Guru dan
Motivasi Kerja Guru dengan Kinerja Guru di SMUK Penabur Jakarta". Jurnal Pendidikan Penabur No.3 th 3. Desember 2004

[8] Robbins, Stephen. "Organizational Behavior”. New Jersey: Pearson, 2011

[9] Schemerhorn. "Organizational Behavior".USA: John W and Son's Inc, 2010

[10]Sutapa, Mada. "Buku Pegangan Kuliah Komunikasi Organisasi Pendidikan". Yogyakarta: FIP Universitas Negeri Yogyakarta, 2007 